\title{
Experimental Study on Performance Parameters of Semiconductor Refrigeration Garment for Different Working Conditions
}

\author{
Li-Feng REN ${ }^{1,2, a *}$, Li MA ${ }^{1,2, b^{*} \text {, Chang-Chun LIU }}{ }^{1,2, c}$ and Xi-Mei DING ${ }^{1,2, d}$ \\ ${ }^{1}$ College of Safety Science and Engineering, Xi'an University of Science \& Technology, Xi'an \\ 710054, China \\ ${ }^{2}$ Shaanxi Key Laboratory of Prevention and Control of Coal Fire, 58, Yanta Mid. Rd., Xi'an, Shaanxi \\ 710054, PR China \\ a lifengrr@126.com, ${ }^{b}$ mal@xust.edu.cn, c keepspring@126.com, ${ }^{\mathrm{d}}$ 303285835@qq.com \\ *Corresponding author Li-Feng Ren and Li Ma
}

Keywords: High-temperature radiation, Hot work environment, Thermoelectric refrigeration, Semiconductor cooling suits, Heat-dissipating methods.

\begin{abstract}
Hot and humid environments are ubiquitous in some special workplaces, such as deep mines, aviation, and military territories. High-temperature radiation is a serious threat to the health of high temperature operation personnel. Exposed to high temperatures for a long time will inevitably lead to dehydrations, heatstroke, or even death. Based on the particularity of the hot work environment, as well as the principle of thermoelectric refrigeration, the related properties of semiconductor cooling garments was studied, which provided some basis for further design. To determine the optimal working conditions of cooling garment with the help of a water-cooled radiator, voltage from 0 to $12 \mathrm{~V}$ was adopted to find the optimal voltage. Meanwhile, the refrigeration performance was tested for different mass flows and heat-dissipating methods. The studies showed that for two water different radiators, the aluminum water-cooled radiator was viewed as the optimal choice for the refrigeration garment. For the semiconductor refrigeration garment, there was an optimal working voltage of $2 \mathrm{~V}$. Among these four different mass flows, the flow of $0.0056 \mathrm{~kg} / \mathrm{s}$ was the optimal choice under the experimental conditions. Among these four different combinations of cooling methods, the effect of a combination of water cooler and radiating film was the best, whereas the combination of water cooler and fan was the worst, however, water cooling was second to none under the experimental conditions.
\end{abstract}

\section{Introduction}

Hot and humid environments are ubiquitous in some special workplaces, such as deep mines, aviation's, and military territories [1, 2]. Heat damage not only affects workers physical health, but also makes their work enthusiasm and work efficiency greatly reduced, which increase incident rate and even lead to dehydration, heatstroke, or death [3]. In recent years, thermal damage, whose prevention and control have become one of the major threats for workers working at high temperature, has to be solved, which not only seriously affects the physical and mental health of workers, but also influences the work efficiency. To remove the hazards resulting from long-term exposure to hot environments, it is necessary to eliminate or reduce heat accumulation in the body [4]. With the development of thermoelectric material (TEM) [5, 6] and thermoelectric cooling technology [7, 8], its cooling performance has been significantly improved. The heat absorbed by the Bi-Te system was 28.42 \% higher than that by the $\mathrm{Pb}-\mathrm{Te}$ [9]. In addition, it has been applied in all walks of life, such as net zero energy buildings [10], thermoelectric refrigerator [11], a thermoelectric cooler for CPU [12], and thermoelectric air-conditioning system [13]. Cooling efficiency of the semiconductor is greatly affected by temperature of its hot and cold sides if others maintained at the same conditions. Thus, it is possible to improve cooling efficiency of the semiconductor by different heat transfer conditions. There are such four common heat dissipation ways as fan cooling, heat pipe cooling, heat pipe with fan cooling and water cooling. Among these methods, the performance of heat transfer with water cooling is the best [14]. Furthermore, coefficient of performance (COP) in the thermoelectric 
refrigeration was improved by the optimization of heat dissipation [15]. The heat exchange systems, comprising a water-air system, a finned heat sink with fan and a heat pipe with fan, were studied, which demonstrated that relevant improvements can be made in efficiency of thermoelectric cooler (TEC) by the proper optimization of the heat exchangers [16]. For higher COP in liquid chiller, a thermoelectric module with relatively long thermoelements is needed [17]. Han et al. [18] obtained the influence on refrigerating capacity of semiconductor and the interaction between heat emission and the voltage. In this study, the optimal working condition of semiconductor refrigeration garment was determined, including its working voltage, cooling methods, and mass flow.

\section{Experimental System}

\section{Experimental Equipment}

As shown in Fig. 1, this experimental system consists of five parts including the thermoelectric cooling system, water-cooled system, data collecting system, high temperature environment simulation system, and temperature control system. Among these five parts, the thermoelectric cooling module uses the type of TEC -12708 semiconductor chiller, whose dimension is $40 \times 40 \times 3.4$ $\mathrm{mm}^{3}$ [19]. Other parameters included the maximum temperature difference of $66^{\circ} \mathrm{C}$, the maximum current of $8 \mathrm{~A}$, the maximum voltage of $12 \mathrm{~V}$, and the maximum cooling capacity of $68.9 \mathrm{~W}$. During the experiment, the chiller was connected with an adjustable power supply to find the optical voltage. As for the cooling system, the water-cooled box was used to meet the cooling demand of hot end, through connecting the chiller hot side with an aluminum water-cooled box, whose dimension is $40 \times 40 \times 10 \mathrm{~mm}^{3}$. To ensure sufficient circulation water in the cooling box, the cooling box was made into an "E-shaped" structure. The accuracy of ADAM 4018/4018+ data acquisition module can reach $0.1 \%$, which can realize the function of overvoltage protection. With regarding to high temperature environmental simulation system, water bath was adopted for heat preservation. For the temperature control system, the temperature controller was applied to ensure the ambient temperature of $40{ }^{\circ} \mathrm{C}$, which was governed by a relay.

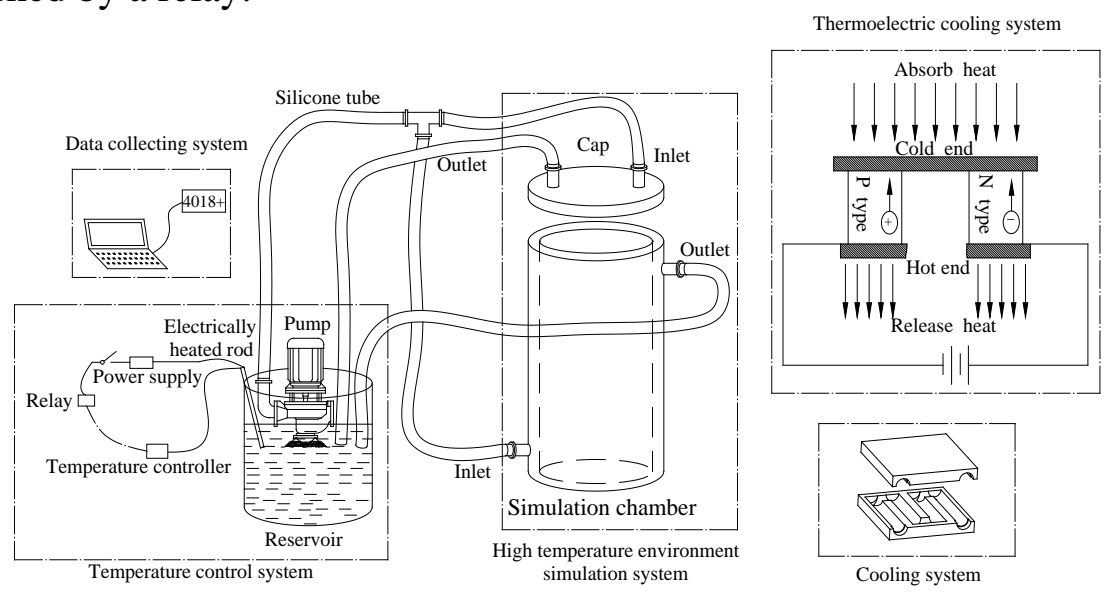

Fig. 1 Experimental system

\section{Measurements}

At the external temperature of $33{ }^{\circ} \mathrm{C}$, the simulation chamber is set to $40{ }^{\circ} \mathrm{C}$ through water-bath heating. The adjustable power supply provides the semiconductor chiller with different voltages from 0 to $12 \mathrm{~V}$. The operating current and voltage of pump are $0.81 \mathrm{~A}$ and $12 \mathrm{~V}$ respectively. The circulating water flow rate of water cooling box was controlled by a glass rotameter. The circulating water temperature keeps for $40{ }^{\circ} \mathrm{C}$ during the experiment. To improve accuracy, the experiments were repeated at least five times to ascertain the recorded data accurate enough. 


\section{Results and Analysis}

\section{Analysis of the Temperature of Cold Side for Different Water-Cooled Radiator}

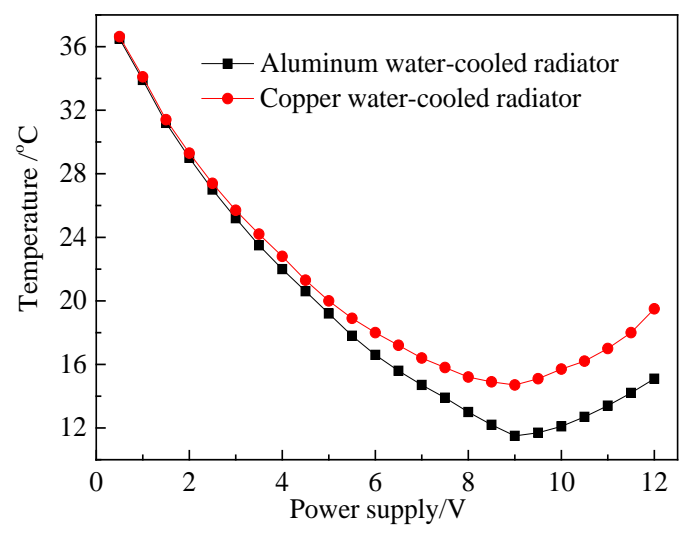

Fig. 2 Temperature profile of cold side for different water-cooled radiators.

There exists an optimal initial steady current which provides the maximum cooling temperature enhancement [20]. First of all, two kinds of water-cooled radiator for different materials, copper and aluminum, were tested. As shown in Fig. 2, for water-cooled radiator of different materials, TEC's cold side temperature decreased first and increased afterwards, which reached the minimum at the input voltage of $9 \mathrm{~V}$. Furthermore, TEC's cold side temperature difference between them became larger and larger, but they were so close when the voltage was less than $5 \mathrm{~V}$. In addition, the cooling effect of copper water-cooled radiator is more obvious than that of an aluminum radiator, but the mass of copper is twice higher than aluminum for the same volume. Based on all these factors, the aluminum water-cooled radiator is viewed as the optimal choice for the refrigeration garment. Thus, the following research centered on it.

\section{Analysis of the Cold Side Temperature for Different Mass Flows}

In the experiment, TEC's cold side temperature was obtained while providing it with different mass flows. The results are shown in the Fig. 5.

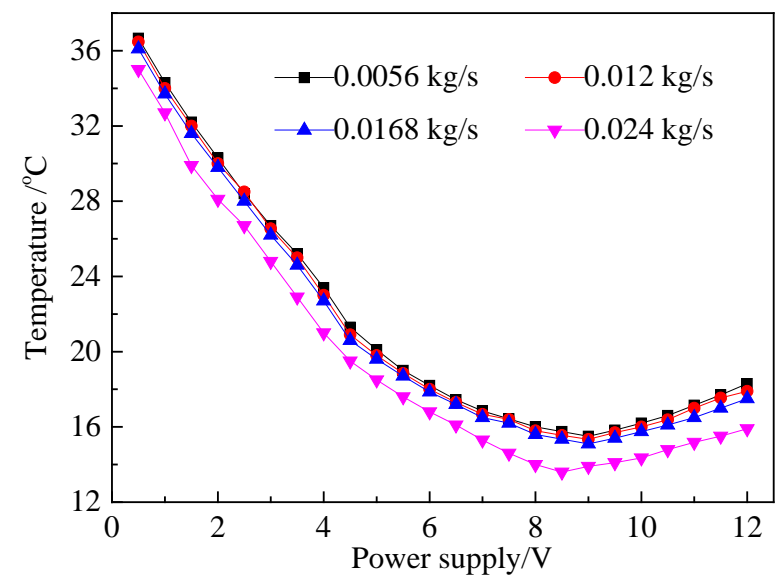

Fig. 3 Temperature profile of cold side with different mass flows.

It is shown in Fig. 3 that the temperature decreased with the increasing flow rate. However, their mutual temperatures were so close for the flows of $0.0056,0.012$, and $0.0168 \mathrm{~kg} / \mathrm{s}$, which showed a relatively significant decrease at the flow of $0.024 \mathrm{~kg} / \mathrm{s}$. Since our purpose is to determine the appropriate mass flow of the refrigeration garment, which means comprehensive factors should be taken into consideration, like body comfort, instead of simply paying attention to the cooling effect. On one hand, the body will be unbearable if the flow rate is too large. On the other hand, the cooling 
effect will not be enough for refrigeration if it is too small. Based on all these factors, the flow of $0.0056 \mathrm{~kg} / \mathrm{s}$ is the optimal choice under the experimental conditions.

\section{Analysis of Temperature of Cold Side for Different Tec Input Voltages}

To gain the optimal voltage of refrigeration, the temperature of the cold side was tested for different TEC input voltage.

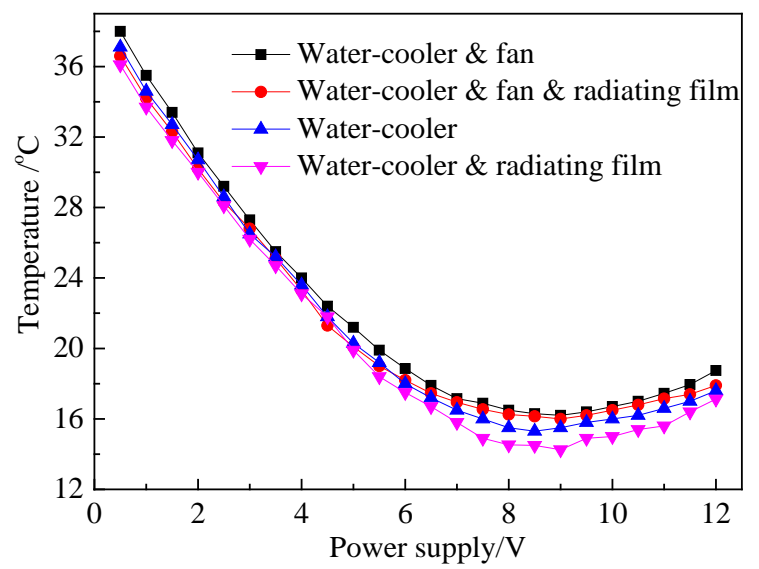

Fig. 4 Temperature profile of cold side for different power supplies.

As shown in Fig. 4, the temperature trend of cold side presented obvious regularity respectively in spite of four different cooling modes, which include a water cooler, a combination of water cooler and fan, a combination of water cooler and radiating film, as well as a combination of water cooler, fan, and radiating film. The temperature of cold side declined to the minimum and then rose with the increasing TEC's input voltage, which meant there was a minimum temperature of cold side during the effective voltage range. As for refrigeration garment, however, the temperature range is an extremely important parameter for designing. Based on long-term investigations of many scholars, a proper comfortable degree of human body was established which included the garment microclimate temperature of $32 \pm 1{ }^{\circ} \mathrm{C}$, humidity of $50 \% \pm 10 \%$ and the airflow of $25 \pm 15 \mathrm{~cm} / \mathrm{s}$ [21]. Here, since there is a demand for comfort in human clothes, the more appropriate method is to make microclimate of the garment within the temperature $32 \pm 1{ }^{\circ} \mathrm{C}$. However, our experimental subject is a dummy model. Ignoring problems of its heat radiation and air flow, the TEC input voltage of $2 \mathrm{~V}$ is selected as the optimum voltage.

\section{Analysis of Temperature of Cold Side for Different Heat-Dissipating Methods}

Wang et al [14] studied the effect of four different heat-dissipating methods on refrigeration performance, which includes air-cooler, water-cooler, heat-pipe, as well as a combination of heatpipe and fan. This part is aimed to investigate some heat-dissipation methods related to water-cooler.

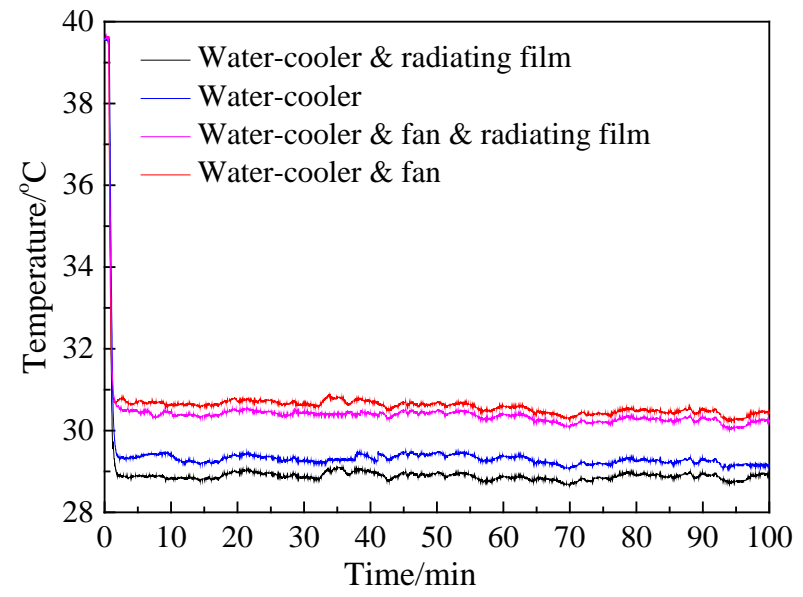

Fig. 5 Temperature profile of cold side for different heat-dissipation methods. 
The temperature of cold side for different heat-dissipation methods is directed in Fig. 5. Among these heat-dissipation methods, a combination of water-cooler and radiating film is the best way, whereas a combination of water-cooler and fan is the worst. Thus, it showed that the radiating film was favorable to heat dissipation of hot side, while the fan was unfavorable to that of hot side. That is the reason why the TEC cold side temperature with fan cooling is higher than others. Moreover, water cooling has been able to achieve the demand of body comfort and simplify the radiating structure compared with other methods, accordingly it can be regarded as the best choice under the experimental conditions. So far, we have discussed the effect of different mass flows, TEC input voltage and heat-dissipation methods on refrigeration performance, primarily referring to the temperature of cool side. In general, the optimal working conditions have been determined, which includes the flow rate of $0.0056 \mathrm{~kg} / \mathrm{s}$, the power supply of $2 \mathrm{~V}$ and the radiating method of pure water cooler.

\section{Conclusion}

Many tests have been implemented on the basis of the water cooler heat dissipation. First, the material of water cooler and the optimal flow rate were carried out, and then the temperature of cold side was recorded while changing the heat-dissipation ways and TEC input voltages. The results can be concluded as follows:

(1) For two different water radiators, the aluminum water-cooled radiator was viewed as the optimal choice for the refrigeration garment; For the semiconductor refrigeration garment, the optimal working voltage was $2 \mathrm{~V}$.

(2) The temperature reduced with the flow rate increasing, but their mutual temperatures were so closed at the rate of $0.0056,0.0112$, and $0.0168 \mathrm{~kg} / \mathrm{s}$, which showed a relatively significant decrease at the rate of $0.0224 \mathrm{~kg} / \mathrm{s}$. However, the flow of $0.0056 \mathrm{~kg} / \mathrm{s}$ was the optimal choice under the experimental conditions

(3) Among the four different combinations of cooling methods, the effect of a combination of water cooler and radiating film was the best, whereas the combination of water cooler and fan was the worst. However, water cooling was regarded as the best choice under the experimental conditions.

\section{Acknowledgement}

The research is supported by the Fund of the National Natural Science Foundation of China (no.51504187, no.51574193, and no. 51604215), the Industrial Science and Technology project of Shaanxi Province (no.2016GY-192) and China Postdoctoral Science Foundation (2016M590962) and all colleagues who previously provided support technically and experimentally.

\section{References}

[1] X.L. Shi, N. Zhu, G.Z. Zheng, The combined effect of temperature, relative humidity and work intensity on human strain in hot and humid environments, Building and Environment 69 (2013) 7280.

[2] Wen Yi, Albert P.C. Chan, Francis K.W. Wong, Del P. Wong, Effectiveness of a newly designed construction uniform for heat strain attenuation in a hot and humid environment, Applied Ergonomics 58 (2017) 555-565.

[3] W. Yi, APC. Chan, Optimizing work-rest schedule for construction rebar workers in hot and humid environment, Building and Environment 61 (2013) 104-113. [4] G. Bartkowiak, A. Dabrowska, A. Marszalek, Assessment of an active liquid cooling garment intended for use in a hot environment, Applied Ergonomics 58 (2017) 182-189.

[5] C. Gayner, KK. Kar, Recent advances in thermoelectric materials, Progress in Materials Science 83 (2016) 330-382. 
[6] Z.M. Ding, L.G. Chen, F.R. Sun, Optimum performance analysis of a combined thermionic-thermoelectric refrigerator with external heat transfer, Journal of the Energy Institute 88 (2015) 169-180.

[7] A. Martinez, D. Astrain, P. Arangurena, Thermoelectric self-cooling for power electronics: Increasing the cooling power, Energy 112 (2016) 1-7. [8] Z.B. Liu, L. Zhang, G.C. Gong, H.X. Li, G.F. Tang, Review of solar thermoelectric cooling technologies for use in zero energy buildings, Energy and Buildings 102 (2015) 207-216.

[9] S. Palaniappan, B. Palanisamy. Finite element analysis of thermoelectric refrigeration system, Procedia Engineering 64 (2013) 1056-1061.

[10] L.M. Shen, X.W. Pu, Y.J. Sun, J.D. Chen, A study on thermoelectric technology application in net zero energy buildings, Energy 113 (2016) 9-24.

[11] N. Karwa, C. Stanley, H. Intwala, G. Rosengarten, Development of a low thermal resistance water jet cooled heat sink for thermoelectric refrigerators, Applied Thermal Engineering (2016) 1-7.

[12] H.M. Hu, T.S. Ge, Y.J. Dai, R.Z. Wang, Experimental study on water-cooled thermoelectric cooler for CPU under severe environment, international journal of refrigeration 62 (2016) 30-38.

[13] L.M. Shen, F. Xiao, H.X. Chen, S.W. Wang, Investigation of a novel thermoelectric radiant air-conditioning system, Energy and Buildings 59 (2013) 123-132.

[14] Y. Wang, J.Y. Zhu, Y.F. Pang, Comprehensive experimental study on many heat Transfer methods of hot side on semiconductor refrigeration, Take the road of the Chinese creation - Annual Conference Proceedings of China Refrigeration Institute in 2011, Nanjing, Jiangsu, China.

[15] D. Astrain, J.G. Vian. M. Dominguez, Increase of COP in the thermoelectric refrigeration by the optimization of heat dissipation, Applied Thermal Engineering 23 (2003) 2183-2200.

[16] D. Astrain, P. Aranguren, A. Martínez, A. Rodríguez, M.G. Pérez, A comparative study of different heat exchange systems in a thermoelectric refrigerator and their influence on the efficiency, Applied Thermal Engineering 103 (2016) 1289-1298.

[17] A. Y. Faraji, H.J. Goldsmid, A. Akbarzadeh, Experimental study of a thermoelectrically-driven liquid chiller in terms of COP and cooling down period, Energy Conversion and Management 77 (2014) 340-348.

[18] T.H. Han, G.F. Tang, G.C. Gong, T. Li, Z.B. Liu, Experimental study of performance of thermoelectric refrigerator under different intensity of heat emission, Hunan University Natural Sciences 36 (2009) 127-130.

[19] T.H. Guo, B.F. Shang, B. Duan, X.B. Lu, Design and testing of a liquid cooled garment for hot environments, Journal of Thermal Biology 49 (2015) 47-54.

[20] M. Ma, J.L. Yu, Experimental study on transient cooling characteristics of a realistic thermoelectric module under a current pulse operation, Energy Conversion and Management 126 (2016) 210-216.

[21] M.X. Gu, Y.C. Sun, C.L. Song, Study of factors affecting the micro-climate comfort of inner clothing, Shandong Textile Science and Technology 4 (2008) 51-53. 